\title{
ANALISISIS KEWENANGAN PEMERINTAHAN DAERAH DALAM MENAMBAH PAD DI KABUPATEN MAYBRAT PROVINSI PAPUA BARAT
}

\author{
Bernard Sagrim ${ }^{1}$, Khasan Effendy ${ }^{2}$, Ngadisah $^{3}$, Sampara Lukman $^{4}$ \\ 1,2,3,4 Institut Pemerintahan Dalam Negeri (IPDN) \\ Email: bernardsagrim05@gmail.com
}

\begin{abstract}
Abstrak
Kabupaten Maybrat merupakan salah satu kabupaten yang terletak di provinsi Papua Barat berdasarkan undang-undang no 13 tahun 2009 sebagi hasil pemekaran Kabupaten Sorong. Sebagai daerah otonomi baru Kabupaten Maybrat perlu meningkatkan pendapatan asli daerah (PAD) untuk kesejahteraan masyarakatnya. PAD merupakan deskripsi potensi keuangan daerah terutama dari pajak dan retribusi daerah. Sampai saat ini pemerintah daerah kabupaten Maybrat dirasakan belum memberikan peran optimal dalam terhadap peningkatan PAD. Penelitian ini berutujuan untuk menganalisis kewenangan yang dimiliki pemerintah kabupaten Maybrat dalam usaha menambah PAD. Penelitian ini menggunakan desain kualitatif dengan menggunakan paradigm post positivisme, yang berusaha mengungkapkan realitas sosial yang secara ontologis tidak pernah bisa dipahami secara utuh karena keterbatasan sifat manusia. Hasil penelitian mengungkapkan dalam konteks otonomi khusus memberikan kewenangan yang lebih luas kepada pemerintah daerah dalam mengoptimalkan segala potensi yang ada untuk meningkatkan Pendapatan Asli Daerah (PAD) seperti dalam hal mengelola ekonomi, tata kelola pemerintahan, urusan pelayanan dan kerjasama kepada pihak lain.
\end{abstract}

Kata Kunci: Kewenangan Pemerintah, Pendapatan Asli Daerah, Otonomi Khusus.

\begin{abstract}
Maybrat Regency is one of the provinces located in West Papua province which was formed based on Law No. 13 of 2009 as a result of the division of Sorong Regency. As a new autonomous region, Maybrat Regency needs to increase local revenue (PAD) for the welfare of its people. Original Regional Income is a picture of the potential for regional finance which is generally based on local taxes and levies. Until now, the regional government of Maybrat district has not played an optimal role in increasing PAD. This study aims to analyze the authority possessed by the Maybrat district government in an effort to increase local revenue. This research uses a qualitative design using the post positivism paradigm, which seeks to reveal a social reality that ontologically can never be fully understood due to the limitations of human nature. The research results reveal that in the context of special autonomy, it gives wider authority to local governments in optimizing all the potential that exists to increase local revenue (PAD), such as in terms of managing the economy, governance, service affairs and cooperation with other parties.
\end{abstract}

Keywords: Government Authority, Regional Original Revenue, Special Autonomy. 


\section{A. PENDAHULUAN}

Pada era Desentralisasi dan Otonomi seperti saat ini, daerah diberikan otoritas yang lebih luas dalam mengatur dan menjalankan pemerintahannya sendiri (Yani, 2002; Sidik, 2002; Safitri, 2016).. Hal ini dimaksudkan agar memangkas birokrasi dan mendekatkan pelayanan publik, memudahkan kontrol publik terhadap penggunaan dana Anggaran Pendapatan dan Belanja Daerah (APBD) dan menciptakan daya saing antar sesama daerah sehingga memunculkan kreativitas (Akbar, 2017; Nurcholish, 2005). Diharapkan pula dengan adanya otonomi ini pemerintah daerah bisa mencari sumber-sumber pendapatan daerah dalam rangka memenuhi kebutuhan pembangunan melalui pendapatan asli daerah (Utomo, 1997; Riduansyah, 2010; Dewi, 2002).

Dengan semakin banyaknya pelimpahan wewenang dari pemerintah pusat kepada pemerintah daerah maka tuntutan untuk meningkatkan pendapatan asli daerah semakin besar pula Tuntutan peningkatan PAD semakin besar pula. Walaupun sampai sejauh ini dana yang disalurkan oleh pusat ke daerah masih cukup besar yakni sekitar 25 persen dari Penerimaan Dalam Negeri dalam APBN sebagai bentuk dana dalam rangka mendukung pelaksanaan otonomi daerah, namun, daerah tetap harus dapat mencari sumber-sumber dana lainnya untuk miningkatkan pendapatan asli daerahnya. Semaksimal mungkin segala potensi harus bisa dioptimalkan dengan tetap mematuhi peraturan dan perundang-undangan yang berlaku. Salah satunya adalah sumber pemasukan dari pajak daerah dan retribusi daerah yang memang telah sejak lama menjadi unsur PAD yang utama (Prana, 2019; Tahar \& Zakhiya, 2016).

Kabupaten Maybrat merupakan daerah yang memiliki berbagai potensi alam maupun manusia yang mampu meningkatkan kesejahteraan masyarakatnya. Salah satu potensi yang dimiliki oleh Kabupaten Maybrat ialah sumber daya alam yang melimpah. Kondisi tersebut dapat dilihat dari posisi strategis Kabupaten Maybrat terutama pengunungan dan lerenglereng yang meliputi Distrik Ayamaru, Ayamaru Utara, Mare, Aifat, Aifat Timur, dan sebagian Aitinyo, serta dataran rendah meliputi sebagian Distrik Aitinyo. Posisi strategis tersebut berpengaruh terhadap potensi sumber daya alam terutama energi seperti minyak, gas, panas bumi, dan batu bara, serta sumber daya mineral seperti batu gamping, batu phospat, batu gamping dolomit, marmer dan kwarsit, tanah liat, dan pasir kwarsa (Cipta Karya, 2005).

Selain sumber daya energi dan mineral, Kabupaten Maybrat juga memiliki potensi pengembagan tanaman pangan, industri dan perkebunan yang dillihat dari jenis tanah, keterangan, kesuburan, dan ketersediaan air. Jenis tanaman pangan yang dapat menjadi komoditas bagi Kabupaten Maybrat ialah seperti padi lading, padi sawah, jagung, kedelai, dan kacang hijau. Sedangkan pada konteks perkebunan potensi di Kabuaten Maybrat dapat 
melalui tanaman seperti karet, kelapa sawit, kelapa, coklat, kopi, rambutan, mangga, serta pisang. Selanjutnya ialah potensi tanaman hutan seperti merbau maupun sagu, serta potensi non kayu seperti madu hutan, daun, buah, pati, bahan obat, hingga pemandangan alam, flora dan fauna yang mampu menjadi potensi daya tarik wisata hutan di Kabupaten Maybrat. Selain itu, potensi sumber daya lain yang dapat dikembangkan di Kabupaten Maybrat ialah perikanan dan budidaya ikan, terutama pada sektor Kawasan pesisir yang memiliki hutan rawa serta mangrove sebagai tempat pembibitan udang (Cipta Karya, 2005).

Potensi kehutanan juga terlihat melalui pemanfataan tumbuhan paku Diplazium esculentum Swartz yang berkontribusi terhadap pendapatan rumah tangga petani terutama di Distrik Aifat Utara sebesar 42.53 atau \pm 1.55 dengan nilai terbesar sekitar Rp1.250.001.440.000/bulan. Tumbuhan paku tersebut dapat digunakan sebagai kerajinan lokal seperti koba-koba yang berfungsi untuk melindungi diri pada saat hujan, maupun noken yang dipakai saat panen. Selain berbagai potensi sumber daya alam tersebut, Kabupaten Maybrat juga memiliki potensi pariwisata seperti Dana Framu, Danau Uter, serta Puncak Petik Bintang yang diharapkan mampu menjadi peningkatan pendapatan asli.

Potensi-potensi diatas dapat menjadi peluang solusi alternatif dalam peningkatan Pendapatan Asli Daerah (PAD) sebagai penggerak ekonomi daerah. Potensi tersebut terbagi menjadi enam sektor utama, yaitu pertambangan dan mineral, pertanian, perkebunan, kehutanan, kelautan dan perikanan, serta pariwisata. Potensi tersebut perlu dikelola secara optimal sehingga dapat menciptakan benefit yang bermuara pada peningkatan PAD. Adanya potensi tersebut akan memberikan efek tidak hanya pada aspek ekonomi, tetapi juga pembangunan, dan kemandirian daerah. Ketika PAD tersebut ditunjang oleh Dana Dekosentrasi, Dana Alokasi Khusus (DAK), Dana Otonomi Khusus berpeluang meningkatkan belanja daerah yang berujung pada terakomodasinya berbagai kepentingan dan kebutuhan masyarakat secara optimal (Wandira, 2013; Nuarisa, 2013; Mualim, 2010).

Peningkatan PAD juga perlu memenuhi unsur dasar kewenangan yang dimiliki oleh Pemerintah Daerah. Kabupaten Maybrat sendiri secara langsung memiliki wewenang yang didasarkan pada dua regulasi utama yaitu Undang-Undang No. 23 Tahun 2014 tentang Pemerintahan Daerah, serta Undang-Undang No. 21 Tahun 2001 tentang Otonomi Khusus bagi Provinsi Papua. Adanya dua wewenang yang dimiliki oleh Kabupaten Maybrat memberikan keunggulan yang seharusnya dapat dioptimalisasikan dalam bentuk kebijakan dan pengaturan untuk meningkatkan kondisi dan kualitas daerah. Melihat pada berbagai fenomena empirik tersebut, Kabupaten Maybrat membutuhkan suatu rancangan kewenangan yang terintegrasi dalam meningkatkan PAD daerah. Berdasarkan hal tersebut, penulis tertarik 
membuat penelitian tentang analisis kewenangan pemerintah daerah dalam peningkatan pendapatan asli daerah (PAD) di Kabupaten Maybrat Papua Barat.

\section{B. METODE}

Penelitian ini menggunakan pendekatan kualitatif yang diasumsikan oleh penulis sesuai dalam upaya untuk memahami permasalahan yang terdapat di objek penelitian diantaranya terkait dengan tujuan penelitian yang ingin dicapai. Penelitian kualitatif mengkaji sesuatu yang sifatnya alami, memahami sekaligus mengartikan sebuah fenomena yang ada (Thomas, 2003). Penulis memposisikan preferensi penelitian ini menggunakan paradigma post positivisme, yang berusaha mengungkapkan realitas sosial yang secara ontologis tidak pernah bisa dipahami secara utuh karena keterbatasan sifat manusia. Karena itu peneliti menggunakan berbagai sumber data (primer dan sekunder) untuk mampu memahami realitas sosial lebih banyak. Informan kunci yang menjadi sumber data primer juga beragam. Selanjutnya metodologi penelitian akan dijelaskan lebih jauh melalui penjabaran beberapa hal berikut: desain penelitian, kerangka konseptual penelitian, data yang diperlukan, informan/ responden dan cara menentukannya, teknik dan instrument pengumpulan data, teknik analisis data, lokasi dan jadwal penelitian (Kuhn, 1970; Guba, 1990; Denzin, 2010)

\section{HASIL DAN PEMBAHASAN}

Pemerintah membagi urusan Pemerintah Daerah (Pemda) konkuren menjadi dua yaitu wajib dan pilihan. Urusan pemerintahan wajib terdiri dari pelayanan dasar dan non-pelayanan dasar, sedangkan urusan pilihan disesuaikan dengan kebutuhan dari kondisi geografis daerah. Pada konteks urusan wajib, Pemda Kabupaten Maybrat memiliki tanggung jawab pada berbagai urusan tersebut untuk dilaksanakan secara optimal, sedangkan pada urusan pilihan disesuaikan dengan kebutuhan Kabupaten Maybrat itu sendiri sesuai dengan karakteristik daerah seperti potensi daerah, letak geografis, kondisi sosial dan keadaan khusus lainnya.

Pemerintah Kabupaten Maybrat sendiri saat ini sedang berbenah dalam mengatur dan mengurus "rumah tangga" mereka sendiri. Hal tersebut tertuang dalam Rancangan Pembangunan Jangka Menengah Daerah (RPJMD) yang menjadi manifetasi dari tujuan dan harapan pembangunan daerah dalam lima tahun ke depan. Berdasarkan pemetaan analisis isu strategis di berbagai urusan pemerintahan yang secara keseluruhan menampilkan berbagai kondisi daerah, terutama dalam peningkatan PAD Kabupaten Maybrat dapat dilihat pada tabel berikut: 
ARTIKEL

Tabel 1. Analisis Isu Strategi Berbagai Urusan Pemerintahan Secara Meyeluruh

\begin{tabular}{|l|l|l|}
\hline No & \multicolumn{1}{|c|}{ Urusan Wajib } & \multicolumn{1}{|c|}{ Urusan Pilihan } \\
\hline 1 & Pendidikan & Pertanian \\
\hline 2 & Kesehatan & Perkebunan \\
\hline 3 & Pekerjaan Umum & Peternakan \\
\hline 4 & Perumahan dan Penataan Ruang & Kehutanan \\
\hline 5 & Perencanaan Pembangunan & Energi dan Sumber Daya \\
\hline 6 & Perhubungan & Pariwisata \\
\hline 7 & Lingkungan Hidup & Perikanan \\
\hline 8 & Kependudukan dan Catatan Sipil & Perdagangan \\
\hline 9 & Pemberdayaan Perempuan dan Perlindungan anak & Industri \\
\hline 10 & Keluarga Berencana dan Keluarga Sejahtera & \\
\hline 11 & Sosial & \\
\hline 12 & Ketenagakerjaan & \\
\hline 13 & Koperasi dan UKM & \\
\hline 14 & Penanaman Modal & \\
\hline 15 & Kepemudaan dan Olahraga & \\
\hline 16 & Kesatuan Bangsa dan Politik Dalam Negeri & \\
\hline 17 & Pemerintahan Umum, Kepegawaian dan Persandian & \\
\hline 18 & Pemberdayaan Masyarakat dan Pemerintahan Kampung & \\
\hline 19 & Komunikasi dan Informatika & \\
\hline 20 & Statistik & \\
\hline 21 & Pertanahan & \\
\hline 22 & Kebudayaan & \\
\hline 23 & Ketahanan Pangan & \\
\hline 24 & Kearsipan & \\
\hline
\end{tabular}

Potensi pengembangan wilayah Kabupaten Maybrat yang secara geografis terdiri dari daerah pegunungan namun memiliki danau yaitu Danau Ayamaru dan Danau Uter yang merupakan suatu keunggulan dibidang pariwisata alam. Potensi pariwisata alam Kabupaten Maybrat juga memiliki potensi sumber daya alam lainnya yang sangat potensial yaitu poyensi pertanian/perkebunna, perikanan sesuai dengan karakteristik wilayah dan pitensi tambang minnyak dan gas bumi serta tambang galian golongan $\mathrm{C}$.

Kekuatan yang dimiliki Kabupaten Maybrat adalah potensi pengembangan sektorsektor kegiatan produktif yang dapat menunjang kehidupan masyarakat, berdasarkan potensi lahan, keunikan alam, dan daya saing daerah yang dapat diolah untuk memperol memperoleh nilai tambah, menyediakan lapangan pekerjaan, serta menjadi sumber pemdapatan daerah.

a. Potensi Pengembangan Pertanian, Perkebunan, Perikanan

Potensi pengembangan lahan pertanian dan perkebunan di Kabupaten Maybrat pada dasarnya cukup besar bila memperhatikam luasan dan ketersediaan lahan dan ketersediaan lahan dibagian selatan wilayah kabupaten yang dinilai memiliki kesesuaian lahan bagi pertanian, perkebunan dan perikanan. Lahan yang sesusai bagi pengembangan pertanian, 
perkebunan dan perikanan masih luas dibagian selatan wilayah kabupaten. Potensi pengembangan sketro pertanian di Kabupaten Maybrat selain dilihat dari ketersediaan lahan yang sesuai juga dilihat dari peluang pengembangan dan komoditi yang dapat dikembangkan.

Komoditi ditanam di kebun masyarakat pada umumnya buah-buahan, umbi-umbian, dan sayur-mayur. Komoditi yang sudah menjadi makanan pokok masyarakat harus dilestarikan seperti yang yang umum dikonsumsi oleh masyarakat saat ini yaitu ubi, keladi, dan sagu. Komoditi ini memiliki potensi untuk dikembangkan lebih lanjut untuk memberikan nilai tambah seperti membuat makanan olahan keladi. Langkah awal dalam pengenalan budidaya pertanian dapat dikembangkan kebun rakyat dengan komoditi tersebut secara bertahap dapat ditambah dengan beberapa komoditi lainnya yang sesuai.

b. Potensi Kehutanan

Wilayah Kabupaten Maybrat dari Peta Penetapan Kawasan Hutan dan pengamatan lapangan merupakan daerah yang didominasi oleh kawasan hutan termasuk hutan lindung. Letak wilayah berada di kawasan dalam dari kepala burung wilayah Provinsi Papua barat dan sebagian termasuk wilayah pegunungan tengah. Keberadaan hutan produksi yang dapat dikonversi (HPK) di sebagian wilayah Kabupaten Maybrat dapat dikembangkan sebagai sumber penghasil kayu komersial atau beralih fungsi sebagai kawasan budidaya lain. Sedangkan pemanfaatan ruang pada hutan lindung lebih banyak diarahkan pada pengembangan potensi hutan non kayu dan jasa lingkungan.

Mengembangkan ekonomi masyarakat lokal didalam kawasan hutan lindung, bentukbentuk aktivitas budidaya perlu memperhatikan batasan-batasan yang sesaui ketentuan pemanfaatan ruang yang diperkenankan dilakukan didalam kawasan hutan lindung tersebut. Potensi ekonomi yang dikembangkan dari sektor kehutanan antara lain berupa potensi hasil hutan kayu, non kayu, wisata alam dan jasa lingkungan.

c. Sarana dan Prasarana Perdagangan

Transportasi yang utama adalah transportasi darat dengan menggunakan angkutan pedesaan atau ojek. Sebelum ada infrastruktur jalan, penduduk Distrik Sawiat membawa hasil pertaniannya dengan jalan menuju Teminabuan atau hingga ke jalan menuju Sorong. Saat ini adanya jalan menuju Teminabuan atau Sorong memudahkan penduduk dalam penjualan komoditas pertanian mereka. Pergerakan barang dan jasa inter wilayah melibatkan Sorong sebagai salah satu pusat kegiatan perdagangan di Provinsi Papua Barat. Sorong menjadi pintu keluar dan masuknya barang-barang dari luar daerah, seperti Sulawesi atau Jawa, yang lalu diteruskan ke Maybrat, termasuk juga untuk kegiatan ekspor dan impor. 
Sementara itu, komoditas pertanian Kabupatan Maybrat, khususnya hasil perkebunan perikanan, dapat menjangkau pasar yang lebih luas dengan melalui Sorong. Pergerakan barang inter wilayah ke Kabupatan Maybrat pada umumnya langsung ke Teminabuan. Barang-barang yang langsung didatangkan ini jenisnya beragam dan tidak hanya untuk memenuhi kebutuhan penduduk Teminabuan saja tetapi juga menjangkau distrik-distrik lainnya. Prasarana perdagangan yang tersedia di Kabupatan Maybrat adalah pasar dan took/warung. Berdasarkan data, di Kabupatan Maybrat memiliki 4 unit pasar dan 424 unit warung/took yang persebarannya terbatas di beberapa distrik saja. Pasar induk dan pasar ikan tersedia di Distrik Teminabuan. Sementara itu, di Distrik Aitinyo juga tercatat ada 1 unit pasar namun hingga saat ini bangunan pasar tersebut belum dimanfaatkan. Fasilitas perdagangan berupa warung/toko hanya tersedia di Distrik Inanwatan, Aitinyo, Ayamaru, Moswaren dan Teminabuan.

\section{d. Ketenagakerjaan dan Lapangan Kerja}

Berdasarkan data Badan Pusat Statistik dalam Maybrat Dalam Angka 2018, kegiatan industri yang terdapat di Kabupaten Maybrat merupakan industri kecil berupa industri rumah tangga dan masih bersifat tradisional. Keseluruhan industri kecil berupa industri rumah tangga dan masih bersifat tradisional. Industri pengolahan pangan. Merupakan industri kecil terbanyak di Kabupaten Maybrat, mencakup 48 unit usaha yang mempekerjakan 69 orang tenaga kerja. Industri Kimia dan bahan bangunan terdiri dari 18 unit usaha dengan 31 tenaga kerja. Industri logam terdiri dari 18 unit usaha yang mampu menyerap 22 orang tenaga kerja. Industri kerajinan dan umum terdiri dari 14 unit usaha dan 26 tenaga kerja. Industri kecil yang paling sedikit jumlah unit usahanya adalah industri sandang dan kulit. Industri ini terdiri dari 9 unit usaha dengan 21 orang tenaga kerja. Pada tahun 2009, hanya terdapat 1 industri menengah, yaitu industri di bidang sawmill yang menggunakan 8 tenaga kerja. Usaha sawmill ini dapat memproduksi kayu gergajian hingga $135 \mathrm{~m} 3$ per tahun. Berbeda dengan BPS, menurut data yang bersumber dari Dinas Perindustrian dan Perdagangan dan Penanaman Modal, kegiatan industri di Kabupaten Maybrat merupakan industri kecil rumahan dan bersifat tradisional. Jumlah industri kecil di Kabupaten Maybrat yang tercatat adalah sebesar 18 unit.

Berdasarkan pemaparan sebelumnya, dari semua potensi daerah di daerah Kabupaten Maybrat yang sangat banyak dan luas ini memungkinkan untuk meningkatkan PAD jika dapat diatur secara baik dan menyeluruh. PAD juga dibutuhkan untuk membangun Kabupaten Maybrat menjadi kabupaten yang pembangunan infrastruktur dan suprastrukturnya dapat meningkan setiap tahunnya. Terdapat proyeksi dalam pembangunan 
jangka panjang dalam rencana pembangunan jangka menengah Kabupaten Maybrat yaitu: Peningkatan PAD; Peningkatan Dana Perimbangan; dan Intensifikasi pengelolaan Pendapatan Daerah dilakukan dengan kegiatan penekanan transfer, dan peningkatan penerimaan pembiayaan daerah.

Kabupaten Maybrat memiliki berbagai kewenangan yang didasarkan pada payung hukum UU Pemerintah Daerah dan UU Otonomi Khusus, hal ini dilihat sebagai potensi dasar Pemerintahnya leluasa dalam mengeliminir ketimpangan antar daerah dan memungkinkan adanya daya dorong upaya timbulnya inovasi daerah. Dengan adanya otonomi khusus tersebut diharapkan kabupaten Maybrat lebih bisa mengoptimalkan segala potensi yang ada di daerahnya.

Selama ini anggapan yang beredar adalah pajak daerah dan retribusi daerah merupakan pemberi kontribu si terbesar diantara semua komponen Pendapatan Asli Daerah (PAD), sehingga pajak daerah dan retibusi daerah sangat diidentikkan dengan Pendapatan Asli Daerah (PAD). Disebabkan oleh hal tersebut maka ada kecenderungan Pemerintah daerah lebih fokus meningkatkan pendapatan asli daerahnya pada retribusi daerah dan pajak daerah dan cenderung mengabaikan potensi PAD dari sumber lain seperti penerimaan laba Badan Usaha Milik Daerah dan potensi sumber daya lainnya

Berdasarkan hal tersebut diatas tuntutan untuk bisa memaksimalkan potensi Pendapatan Asli Daerah tidak terkecuali di kabupaten Maybrat semakin besar. Hal ini juga sejalan dengan semakin luasnya kewenangan pemerintah yang diberikan oleh pemerintah pusat kepada pemerintah daerah. .Maka untuk dapat mencapai tujuan tersebut pemerintah kabupaten Maybrat harus secepatnya melakukan segala upaya untuk moendorong peningkatan pendapatan asli daerah untuk tahun yang akan datang. Salah satu usaha yang dapat segera dilakukan adalah dengan memaksimalkan potensi daerah yang ada di kabupaten Maybrat.

\section{KESIMPULAN}

Kewenangan pengelolaan potensi daerah di Pemerintah Kabupaten Maybrat dalam Regulasi Pemerintahan Daerah dan Undang-Undang Otonomi Khusus. Secara umum, kewenangan dalam konteks urusan wajib, Pemerintah Daerah Kabupaten Maybrat bertanggungjawab mengoptimalisasi terhadap berbagai urusan pelayanan dasar dan nonpelayanan dasar, sedangkan pada urusan pilihan disesuaikan dengan kebutuhan Kabupaten Maybrat sesuai dengan karakteristik daerah. Sifat kekhususan daerah otonomi dilihat sebagai prospek yang mampu memberikan efektifitas kewenangan daerah. Kondisi ini menjadi titik 
positif sebagai landasan dalam mendorong pembangunan maupun perkembangan Pemerintah Kabupaten Maybrat.

Pemerintah Kabupaten Maybrat mendapat stimulus pengelolaan pemerintah yang lebih luas dan mampu melakukan percepatan pembangunan. Pemerintah Kabupaten Maybrat sebagai daerah otonomi baru, dari segi pemerintahan memungkinkan dapat melakukan berbagai upaya positif tidak hanya dari aspek pengelolaan pajak daerah namun, potensi daerah seperti SDA, letak geografis, budaya, khas, pemberdayaan berbasis masyarakat, sinergi terhadap 'roda' pemerintahan yang ada. Memanfaatkan dari segala sumber yang ada, potensial, dan mengunggulkan komoditi mampu menjadi strategi yang baik dalam meningkatkan PAD Kabupaten Maybrat sendiri.

\section{DAFTAR PUSTAKA}

Akbal, M. (2017). Harmonisasi Kewenangan Antara Pemerintah Pusat dan Daerah dalam Penyelenggaraan Otonomi Daerah. SUPREMASI: Jurnal Pemikiran, Penelitian Ilmuilmu Sosial, Hukum dan Pengajarannya, 11(2).

Denzin, N. K. (2010). Moments, Mixed Methods, and Paradigm Dialogs. Qualitative Inquiry, 16(6), 419-427.

Dewi, E. (2002). Identifikasi Sumber Pendapatan Asli Daerah Dalam Rangka Pelaksanaan Otonomi Daerah.

Finer, H. (1949). Theory And Practice of Modern Government. H. Holt.

Guba, E. G. (1990). The Paradigm Dialog. In Alternative Paradigms Conference, Mar, 1989, Indiana U, School of Education, San Francisco, CA, US. Sage Publications, Inc.

Jack, F. (2012). How To Design and Evaluate Research in Education. New York: Mc-Graw Hill.

Kothari, C. R. (2004). Research Methodology: Methods and Techniques. New Age International.

Kuhn, T. S. (1970). The Structure of Scientific Revolutions, 2nd enl. ed. University of Chicago Press.

Mualim, M. (2010). Pengaruh Desentralisasi Fiskal terhadap Pertumbuhan Ekonomi dan Peran Kelembagaan Dana Otonomi Khusus Papua di Provinsi Papua Barat. (Doctoral dissertation, Universitas Brawijaya).

Nuarisa, S. A. (2013). Pengaruh PAD, DAU dan DAK terhadap pengalokasian anggaran belanja modal. Accounting Analysis Journal, 2(1).

Nurcholish, H. (2005). Teori dan praktik pemerintahan dan otonomi daerah. Jakarta: Gramedia Widiasarana Indonesia.

Prana, R. R. (2019). Analisis Faktor-faktor yang Mempengaruhi Pendapatan Asli Daerah (PAD) Kota Tebing Tinggi. Jurnal Ilman: Jurnal Ilmu Manajemen, 4(1). 
Riduansyah, M. (2010). Kontribusi Pajak Daerah dan Retribusi Daerah Terhadap Pendapatan Asli Daerah (PAD) dan Anggaran Pendapatan Dan Belanja Daerah (APBD) Guna Mendukung Pelaksanaan Otonomi Daerah (Studi Kasus Pemerintah Daerah Kota Bogor). Hubs-Asia, 10(1).

Safitri, S. (2016). Sejarah Perkembangan Otonomi Daerah di Indonesia. Criksetra: Jurnal Pendidikan Sejarah, 5(1).

Sidik, M. (2002). Perimbangan Keuangan Pusat dan Daerah Sebagai Pelaksanaan Desentralisasi Fiskal. In Makalah Seminar Setahun Implementasi Kebijakan Otonomi Daerah.

Tahar, A., \& Zakhiya, M. (2016). Pengaruh Pendapatan Asli Daerah dan Dana Alokasi Umum terhadap Kemandirian Daerah dan Pertumbuhan Ekonomi Daerah. Journal of Accounting and Investment, 12(1), 88-99.

Thomas, D. R. (2003). A General Inductive Approach for Qualitative Data Analysis. New Zealand: University of Auckland

Utomo, W. (1997). Peranan dan Strategi Peningkatan Pendapatan Asli Daerah (PAD) dalam Pelaksanaan Otonomi Daerah. Jurnal Ilmu Sosial dan Politik, 1(1997).

Wandira, A. G. (2013). Pengaruh PAD, DAU, DAK, dan DBH Terhadap Pengalokasian Belanja Modal. Accounting Analysis Journal, 2(1).

Yani, A. (2002). Hubungan Keuangan Antara Pemerintah Pusat dan Daerah di Indonesia. Jakarta: RajaGrafindo Persada. 